\title{
A CORTE INTERAMERICANA DE DIREITOS HUMANOS E A PROMOÇÃO DO ACESSO À JUSTIÇA
}

\section{THE INTER-AMERICAN COURT OF HUMAN RIGHTS AND THE PROMOTION OF ACCESS TO JUSTICE}

\author{
Cláudio Ladeira de Oliveira* \\ Erika Maeoka**
}

\begin{abstract}
Resumo: $\mathrm{O}$ presente artigo tem por objetivo demonstrar a importância da Corte Interamericana de Direitos Humanos na promoção do direito humano ao acesso à justiça. A partir da análise de sua jurisprudência, são demonstrados os instrumentos de que dispõe a Corte para realizar essa tarefa, bem como as mais importantes limitações impostas a esta competência.
\end{abstract}

Palavras-chave: Acesso à justiça. Corte Interamericana de Direitos Humanos. Direitos humanos.

\begin{abstract}
This article aims to show the relevance of the Inter-American Court of Human Rights in the promotion of the human right to Access to Justice. By using the jurisprudence of the Court, this article shows the instruments available for the Court to conduct that work and the most important limitations faced by this instance.
\end{abstract}

Key-words: Access to Justice. Inter-American Court of Human Rights. Human Rights.

\section{INTRODUÇÃO}

Os direitos humanos, seja qual for sua justificativa teórica, estejam eles positivados em Constituições ou tratados internacionais, objetivam proteger os indivíduos contra as potenciais arbitrariedades do poder Estatal. Seguramente esta não é sua única dimensão, uma vez que a proteção pode eventualmente ser dirigida também contra entidades privadas, por exemplo. No entanto, este é seu sentido "mínimo". Proteger uma esfera elementar de dignidade humana dos cidadãos sujeitos ao poder Estatal soberano. Por outro lado, não é possível implementar os direitos humanos sem a firme atuação de instituições políticas

" Doutor e Mestre em Direito pela Universidade Federal de Santa Catarina e professor da Universidade Estadual de Londrina. E-mail: claudioladeira@ig.com.br.

Mestranda em Direito Negocial e Especialista em Direito do Estado pela Universidade Estadual de Londrina. E-mail: ekmk2005@yahoo.com.br. 
organizadas, dotadas de aparato coercitivo, tribunais, recursos administrativos, capacidade de implementação de políticas públicas etc. Ou seja, a efetividade dos direitos humanos requer Estados organizados e capazes de atuar, ou ao menos entidades cujo poder efetivo depende diretamente de tais estados.

No âmbito do direito internacional uma importante instituição destinada à promoção dos direitos humanos no continente americano é a Corte Interamericana de Direitos Humanos, a qual possui competência - estabelecida pelos Estados-membro - para interpretar a Convenção Americana de Direitos Humanos. E dentre os direitos nela estabelecidos encontram-se os seguintes:

Artigo $8^{\circ}$ - Garantias judiciais

1 - Toda pessoa tem direito a ser ouvida, com as devidas garantias e dentro de um prazo razoável, por um juiz ou tribunal competente, independente e imparcial, estabelecido anteriormente por lei, na apuração de qualquer acusação penal formulada contra ela, ou para que se determinem seus direitos ou obrigações de natureza civil, trabalhista, fiscal ou de qualquer outra natureza.

Artigo $25^{\circ}$ - Proteção judicial

1. Toda pessoa tem direito a um recurso simples e rápido ou a qualquer outro recurso efetivo, perante os juízes ou tribunais competentes, que a proteja contra atos que violem seus direitos fundamentais reconhecidos pela constituição, pela lei ou pela presente Convenção, mesmo quando tal violação seja cometida por pessoas que estejam atuando no exercício de suas funções oficiais.

2. Os Estados Partes comprometem-se:

a) a assegurar que a autoridade competente prevista pelo sistema legal do Estado decida sobre os direitos de toda pessoa que interpuser tal recurso;

b) a desenvolver as possibilidades de recurso judicial; e

c) a assegurar o cumprimento, pelas autoridades competentes, de toda decisão em que se tenha considerado procedente o recurso.

Tais dispositivos não são estranhos à nossa Constituição, a qual estabelece no art. 5, XXX, que "a lei não excluirá da apreciação do Poder Judiciário lesão ou ameaça de direito". Trata-se do problema elementar do "acesso à justiça”, “o modo pelo qual os direitos se tornam efetivos” (CAPPELLETTI; GARTH, 1988, p. 12). No entanto, como ocorre com a interpretação dos direitos humanos em geral, também a amplitude do direito ao "acesso à justiça" é objeto de inúmeras controvérsias. Por exemplo, as rigorosas exigências de um sistema democrático (liberdade de expressão, igualdade política, liberdade de associação) podem exigir uma concretização mais "agressiva" e "ousada" do direito ao "acesso à justiça”. Em outras palavras, é possível que uma versão excessivamente "formal” de acesso à justiça (possibilidade de acesso formal a um processo judicial e direito à sentença de mérito) acoberte o risco de tornar-se mera proclamação solene e vazia se não há a efetiva possibilidade de concretização judicial de direitos fundamentais: 
[...] Uma evolução adequada do sistema de distribuição de justiça equivaleria à predisposição de procedimentos adequados à tutela dos novos direitos. A inércia do legislador - ao menos para dar tutela efetiva às novas situações carentes de tutela - conduz a uma interessante e generosa posição doutrinária: a do direito à adequada tutela jurisdicional. $\mathrm{O}$ direito do acesso à justiça tem como corolário o direito à pré-ordenação de procedimentos adequados à tutela dos direitos [...]. (MARINONI, 1994, p. 7).

O presente artigo analisa tais problemas a partir da atuação da Corte Interamericana de Direitos Humanos.

\section{A INTERNACIONALIZAÇÃO DOS DIREITOS HUMANOS E A JUSTIÇA INTERNACIONAL}

As inomináveis atrocidades praticadas durante a Segunda Guerra Mundial despertaram a consciência da humanidade para a necessidade de refrear esses assassinatos em massa e de se preocupar com a regulamentação dos Direitos Humanos, por meio do qual surgiu o processo de fortalecimento da internacionalização dos Direito Humanos. Piovesan (2003, p. 92) registra que "em face do regime de terror, passa a imperar a lógica da destruição, na qual as pessoas são consideradas descartáveis, em razão de não-pertinência a determinada raça: a chamada raça ariana”. Em razão disso, 18 milhões de pessoas foram enviadas aos campos de concentração, sendo que 11 milhões não sobreviveram e contabilizam-se que nesse universo 6 milhões eram judeus. (PIOVESAN, 2003).

É verdade que formulações teóricas sobre os direitos humanos eram há muito disponíveis no contexto do pensamento jusnaturalista, e também haviam instrumentos jurídicos internacionais que objetivavam garantir alguma proteção a aspectos da dignidade humana. No entanto, reação às barbáries cometidas durante a Segunda Guerra Mundial produziu um resultado institucionalmente inédito. A partir de então adquiriu relevância, de um modo que antes era impensável, a idéia de que a proteção dos Direitos Humanos deve transcender os limites jurisdicionais dos Estados. Nesse sentido, Piovesan $(2000)^{1}$ assinala que a proteção dos direitos humanos "não deve se restringir, confinar-se às muralhas, à competência nacional exclusiva ou à jurisdição doméstica exclusiva, porque revela tema de legítimo interesse da comunidade internacional”. Foi

${ }^{1}$ Texto baseado nas notas taquigráficas proferida no Seminário Internacional "O Tribunal Penal Internacional e a Constituição Brasileira”, promovido pelo Centro de Estudos Judiciários do Conselho da Justiça Federal, em 30 de setembro de 1999, no auditório do Superior Tribunal de Justiça, em Brasília - DF. 
nesse período que, com a Declaração Universal de 1948, os direitos humanos se consolidaram no cenário internacional.

Com o advento do processo de internacionalização dos Direitos Humanos o sistema jurisdicional não se limita mais à circunscrição dos limites territoriais dos Estados. Portanto, é preciso lembrar que há, além dessa esfera, o sistema jurisdicional internacional e, dentro desta estrutura, está disposta uma ramificação do Direito Internacional, que postula a proteção internacional dos Direitos Humanos, por intermédio de uma jurisdição internacional atribuída às Cortes Internacionais.

No âmbito das Américas, a Organização dos Estados da América desenvolveu um sistema de proteção dos direitos humanos composto por dois órgãos de fiscalização: a Comissão Interamericana de Direitos Humanos e a Corte Interamericana de Direitos Humanos. ${ }^{2}$ A jurisdição internacional de proteção dos Direitos Humanos é exercida pela Corte Interamericana, que tem a sua competência delimitada para julgar a responsabilidade internacional dos Estados que aceitaram a sua jurisdição. A Convenção Americana de Direitos Humanos ou pacto de São José da Costa Rica foi o primeiro documento firmado, em 22 de novembro 1969, no qual se consolidou a proteção dos direitos humanos civis e políticos ${ }^{3}$. Posteriormente, por meio de um protocolo adicional, pelo Tratado de São Salvador, foi normatizada, em 17 de novembro de 1988, a proteção dos direitos econômicos, sociais e culturais, que constituem os Tratados mais relevantes de proteção dos Direitos Humanos no âmbito do Sistema Interamericano. ${ }^{4}$

A apreciação dos casos levados às Cortes Internacionais depende da observância do princípio da subsidiariedade ou complementariedade que, conforme Ramos (2005, p. 118), "significa apenas que o próprio Estado, primeiramente por meio de seus recursos internos, deve assegurar o respeito aos direitos humanos". Explica Ramos (2005, p. 118-9) que somente "após, no fracasso de tais meios internos, pode a vítima aceder aos mecanismos internacionais"

${ }^{2} \mathrm{O}$ Estado Brasileiro reconheceu a jurisdição da Corte Interamericana de Direitos Humanos por meio do Decreto Legislativo 89, em 3 de dezembro de 1988, e foi promulgada pelo Decreto 4.463, de 08 de novembro de 2002.

${ }^{3} \mathrm{O}$ Estado Brasileiro aderiu à Convenção Americana de Direitos Humanos por meio do Decreto Legislativo 27, de 25 de setembro de 1992, e foi promulgada pelo Decreto 678, de 06 de novembro de 1992.

${ }^{4} \mathrm{O}$ Estado Brasileiro aderiu ao Protocolo Adicional por meio do Decreto Legislativo 56, de 19 de abril de 1995, e foi promulgada pelo Decreto 3.321, de 30 de dezembro de 1999. 
que remete ao requisito do prévio esgotamento das vias judiciais internas para a interposição das demandas internacionais. Como sugere Piovesan (2006, p. 282) "a sistemática internacional só pode ser invocada quando o Estado se mostrar omisso ou falho na tarefa de proteger os direitos fundamentais."

Assim, o acesso à justiça internacional pressupõe o prévio esgotamento dos recursos internos. Conforme esclarece Lesdema (2007, p. 1), o Sistema Internacional de Proteção opera "sólo después de haber hecho uso de los recursos jurisdiccionales locales, sin haber obtenido un remedio para la violación que se alega". Isto significa que, "el sistema interamericano de protección de los derechos humanos es subsidiario, en el sentido de que debe permitir, en primer lugar, que el propio Estado pueda adoptar las medidas correctivas que sean necesarias" (LESDEMA, 2007, p. 1). Contudo, salienta Lesdema (2007, p. 1) que a regra do prévio esgotamento dos recursos internos implica:

[...] una obligación paralela para los Estados, en cuanto supone la existencia de un aparato judicial que funcione, y que contempla recursos apropriados para proteger a las personas en el ejercicio de sus derechos humanos, es la inexistencia de recursos internos efectivos lo que coloca la víctima en estado de indefensión, y lo que justifica la protección internacional.

Toro Huerta (2005) atenta para os desafios do Poder Judiciário diante da obrigação primária de proteção dos direitos humanos ao esclarecer que:

[...] en el ámbito de los derechos humanos, los jueces, como garantes de tales derechos en el orden interno, desempeñan una misión fundamental de garantía y control de los poderes públicos. Asimismo, en tanto agentes del Estado, los jueces nacionales son la pieza clave en la aplicación de la regla de previo agotamiento de los recursos internos al ser los derechos humanos reconocidos en el ámbito internacional antes de que un caso se presente ante una instancia internacional; en este sentido, los jueces son en gran medida los operadores primarios del principio de subsidiariedad propio del DIDH. (p. 329-30).

Como assinala Trindade (1998, p. 19):

[...] a regra do prévio esgotamento dos recursos internos dá testemunho da interação entre o direito internacional e o direito interno no presente contexto de proteção; os recursos internos formam parte integral da própria proteção internacional dos direitos humanos, recaindo a ênfase na capacidade de tais recursos de remediar a situação impugnada e reparar os danos causados, e não no processo mecânico de esgotamento.

Assim, são pontos fundamentais do sistema interamericano de proteção tanto a atuação subsidiária da justiça internacional quanto a obrigação primária dos Estados em promover a proteção direitos humanos. Segundo Abregú, mesmo sendo o Direito Internacional que impõe às obrigações aos Estados signatários: 
[...] será el derecho local el que decidirá, en la práctica, la vigencia de un derecho. En este sentido, no debe ignorarse que sólo la efectiva protección en el ámbito interno puede asegurar la vigencia de los derechos internacionalmente reconocidos: la distancia entre los órganos internacionales de protección y el individuo cuyos derechos ha sido indebidamente restringidos, la escasa cantidad de casos que llegan a la esfera internacional y los valores republicanos que explican el principio de economía procesal, son sólo algunos ejemplos de la necesidad de una mayor inmediatez en la protección de los derechos. (ABREGÚ, 2004, p. 6).

Com efeito, somente nos casos em que existam restrições perante a jurisdição doméstica torna-se possível a interposição das ações internacionais. Incumbe observar que esses obstáculos são as limitações ao princípio do acesso à justiça que são corrigidos por intermédio da atuação das Instâncias Internacionais, que evidenciam a relação direta entre a razão da existência das Cortes Internacionais e o acesso à justiça. Portanto, verifica-se que a jurisdição internacional constitui uma via pela qual é suprimida a deficiência da ordem jurídica interna na promoção dos Direitos Humanos.

\section{O ACESSO À JUSTIÇA E A CONVENÇÃO AMERICANA DE DIREITOS HUMANOS}

O acesso à justiça não está somente consagrado nas disposições constitucionais e legais internas. Igualmente, encontra-se previsto nos Tratados Internacionais de Proteção dos Direitos Humanos. No Sistema Interamericano, verifica-se que o princípio do acesso à justiça está consagrado na Convenção Americana nos artigos 8 e 25 .

Como menciona Cançado Trindade (1998, p. 19), esse dever constitui um pilar básico não somente de tais Tratados, como do próprio Estado de Direito em uma sociedade democrática, e sua aplicação correta tem o sentido de aperfeiçoar a administração da justiça material e não somente formal em nível nacional.

Conforme Ventura Robles (2008) o acesso à justiça expressa a "posibilidad de toda persona, independientemente de su condición económica o de otra naturaleza, de acudir al sistema previsto para la resolución de conflictos y vindicación de los derechos protegidos de los cuales es titular". Isto significa que, pode-se entender a ação, diante de uma controvérsia ou a necessidade de esclarecimento de um fato, como a possibilidade de socorrer-se dos meios previstos pelos ordenamentos jurídicos nacionais e internacionais para solucionar a respectiva questão. (VENTURA ROBLES, 2008).

Cançado Trindade (2007) postula que "el derecho de acceso a la justicia, dotado de contenido jurídico própio", expressa "el derecho a obtener justicia. 
Configúrase, así, en suma, como el derecho a la propia realización de la justicia”. (p. 653, grifos do autor).

Cintra, Grinover e Dinamarco (2003) esclarecem a inter-relação entre a justiça das decisões e o acesso à justiça ao mencionar que:

[...] seja nos casos de controle jurisdicional indispensável, seja quando simplesmente uma pretensão deixou de ser satisfeita por quem podia satisfazê-la, a pretensão trazida pela parte no processo clama por uma solução que faça justiça a ambos os participantes do conflito e do processo. Por isso é que se diz que o processo deve ser manipulado de modo a propiciar às partes o acesso à justiça, o qual se resolve, na expressão muito feliz da doutrina brasileira recente, em acesso à ordem jurídica justa. (p. 33, grifo dos autores).

Essas considerações, mormente, são relevantes para compreender o papel da justiça internacional, que atua nos casos em que, salvo as exceções, já houve a atuação da jurisdição interna. $\mathrm{O}$ que significa que $\mathrm{o}$ acesso à justiça não se revela apenas como o acesso formal, mas o verdadeiro acesso à justiça significa que a decisão deve ser revestida de justiça.

Para Cintra, Grinover e Dinamarco (2003) o "acesso à justiça não se identifica, pois, com a mera admissão ao processo, ou possibilidade de ingresso em juízo" (p. 33, grifo dos autores). Sob essa perspectiva a Comissão Interamericana menciona que o direito internacional dos direitos humanos "ha desarrollado estándares sobre el derecho a contar con recursos judiciales y de otra índole que resulten idóneos y efectivos para reclamar por la vulneración de los derechos fundamentales" (COMISIÓN INTERAMERICANA DE DERECHOS HUMANOS, 2007, p. 7).

Esses princípios desenvolvidos passam a exigir dos Estados não só a obrigação negativa de não impedir o acesso aos recursos, mas, igualmente, a obrigação positiva de organizar o aparato institucional para que todos os indivíduos possam acender aos recursos, e para isso impõe-se ao Estado o dever de remover os obstáculos normativos, sociais ou econômicos que impedem ou limitam a possibilidade de concreto acesso à justiça. (COMISIÓN INTERAMERICANA DE DERECHOS HUMANOS, 2007, p. 8).

O fundamento albergado na Convenção Americana de Direitos Humanos, que estabelece a obrigatoriedade da proteção efetiva dos direitos humanos, está previsto em seu art. 1.1 que estabelece:

[...] os Estados-parte nesta Convenção comprometem-se a respeitar os direitos e liberdades nela reconhecidos e a garantir seu livre e pleno exercício a toda pessoa que esteja sujeita à sua jurisdição, sem discriminação alguma, por motivo de raça, cor, sexo, idioma, religião, opiniões políticas ou de qualquer natureza, origem nacional ou social, posição econômica, nascimento ou qualquer outra condição social. 
Os dispositivos que prevêem o acesso à justiça em caso de violação de Direitos Humanos são os artigos 8.1 e 25.1 da Convenção Americana, já referidos acima. Sobre o primeiro artigo, comenta Ventura Robles (2008) que:

[...] esta disposición es clara y según ella, los Estados no deben interponer trabas a las personas que acudan a los jueces o a los tribunales en busca de que sus derechos sean protegidos o determinados. Consecuentemente, cualquier norma o medida estatal, en el orden interno, que dificulte de cualquier manera, uno de ellos puede ser la imposición de costos, el acceso de los individuos a los tribunales y que no esté justificado por necesidades razonables de la propia administración de justicia, debe entenderse como contraria a la citada normal convencional.

A Corte define a abrangência da aplicabilidade do artigo $8^{\circ}$ da Convenção ao postular que embora o citado dispositivo titula-se "garantias judiciais" considera que:

[...] su aplicación no se limita a los recursos judiciales en sentido estricto, 'sino al conjunto de requisitos que deben observarse en las instancias procesales' a efecto de que las personas puedan defenderse adecuadamente ante cualquier acto emanado del Estado que puede afectar su derechos. ${ }^{5}$

Ao sopesar as circunstâncias do caso Cantos, a Corte estabeleceu que os Estados tem, como parte de suas obrigações gerais, o dever positivo de garantia em relação aos indivíduos submetidos a sua jurisdição. Isso pressupõe que o Estado deve:

[...] tomar todas las medidas necesarias para remover los obstáculos que puedan existir para que los individuos puedan disfrutar de los derechos que la Convención reconoce. Por consiguiente, la tolerancia del Estado a circunstancias o condiciones que impidan a los individuos acceder a los recursos internos adecuados para proteger sus derechos, constituye una violación del artículo 1.1 de la Convención. ${ }^{6}$

A Corte $^{7}$ manifesta que o artigo 8.1 da Convenção consagra o direito de acesso à justiça, por isso em cumprimento a esta disposição é vedado ao Estado interpor obstáculos às pessoas que recorrem aos juízes e tribunais em busca da proteção ou da determinação de seus direitos. Importa compreender que

${ }^{5}$ CORTE IDH. Caso Ivcher Bronstein vs. Perú. Fondo, Reparaciones y Costas. Sentencia de 6 de febrero de 2001. Serie C n. 74, párr. 4.

${ }^{6}$ Cf. Caso Hilaire, Constantine y Benjamin y otros, supra nota 5, párr. 151; Excepciones al agotamiento de los recursos internos (arts. 46.1, 46.2.a e 46.2.b Convención Americana sobre Derechos Humanos) Opinión Consultiva OC-11/90 del 10 de agosto de 1990. Serie A n. 11, párr. 34.

${ }^{7}$ CORTE IDH. Caso Cantos vs. Argentina. Fondo, Reparaciones y Costas. Sentencia de 28 de Noviembre de 2002. Serie C n. 97, párr. 50. 
qualquer norma ou medida de ordem interna que determine o pagamento de custas ou dificulte de qualquer outro modo o acesso dos indivíduos aos tribunais, que não é justificável em razão da própria necessidade da administração da justiça, devem ser entendidas como contrária ao preceituado no dispositivo mencionado. ${ }^{8}$

A Convenção prevê que as pessoas sob a jurisdição do Estado devem ter acesso "a un recurso sencillo y rápido o a cualquier otro recurso efectivo ante jueces o tribunales competentes, que las ampare contra actos que violen sus derechos fundamentales". ${ }^{9}$ Portanto, o artigo 25.1 da Convenção Americana, segundo as considerações de Ventura Robles (2008):

[...] establece la obligación positiva del Estado de conceder a todas las personas bajo su jurisdicción, un recurso judicial efectivo contra actos violatorios de sus derechos fundamentales, derechos fundamentales que pueden estar reconocidos en la Convención Americana o por la propia ley interna.

Pela perspectiva da Corte, a controvérsia entre as partes deve ser analisada por dois postulados relacionados com a efetividade do recurso: a) se a presumida vítima teria acesso a um recurso; e b) se o tribunal competente teria as faculdades necessárias para restituir à presumida vítima o gozo de seus direitos, em caso de confirmação da violação. O primeiro postulado refere-se à "acessibilidade do recurso" e o segundo à "efetividade do recurso". ${ }^{10}$

Para cumprir com os postulados de acesso à justiça, define a Corte que o Estado deve:

[...] establecer en el ordenamiento jurídico interno un recurso efectivo en los términos de la Convención, los Estados deben promover recursos accesibles a toda persona para la protección de sus derechos. Si una determinada acción es el recurso destinado por la ley para obtener la restitución del derecho que se considera violado, toda persona que sea titular de dicho derecho debe tener la posibilidad real de interponerlo. ${ }^{11}$

Essa possibilidade de real interposição, conforme assinala a Corte Interamericana está condicionada à existência do recurso, pois:

${ }^{8}$ CORTE IDH. Caso Cantos vs. Argentina. Fondo, Reparaciones y Costas. Sentencia de 28 de Noviembre de 2002. Serie C n. 97, párr. 50.

${ }^{9}$ CORTE IDH. Caso Castañeda Gutman vs. México. Excepciones Preliminares, Fondo, Reparaciones y Costas. Sentencia de 6 de agosto de 2008. Serie C n. 184, párr. 102.

${ }^{10}$ CORTE IDH. Caso Castañeda Gutman vs. México. Excepciones Preliminares, Fondo, Reparaciones y Costas. Sentencia de 6 de agosto de 2008. Serie C n. 184, párr. 103.

${ }^{11}$ CORTE IDH. Caso Castañeda Gutman vs. México. Excepciones Preliminares, Fondo, Reparaciones y Costas. Sentencia de 6 de agosto de 2008. Serie C n. 184, párr. 106. 
[...] no basta con que esté previsto por la Constitución o la ley o con que sea formalmente admisible, sino que se requiere que sea realmente idóneo para establecer si se ha incurrido en una violación a los derechos humanos y proveer lo necesario para remediarla. No pueden considerarse efectivos aquellos recursos que, por las condiciones generales del país o incluso por las circunstancias particulares de un caso dado, resulten ilusorios. ${ }^{12}$

Por conseguinte, julga que:

[...] los recursos son ilusorios cuando se demuestra su inutilidad en la práctica, el Poder Judicial carece de la independencia necesaria para decidir con imparcialidad o faltan los medios para ejecutar las decisiones que se dictan en ellos. A esto puede agregarse la denegación de justicia, el retardo injustificado en la decisión y el impedimento del acceso del presunto lesionado al recurso judicial. ${ }^{13}$

Deve-se recordar ainda que, a efetividade dos recursos exige a observância da duração razoável. Nesse sentido, manifesta que :

[...] acceso a la justicia tiene relación con la efectividad de los recursos, ya que no es posible afirmar que un recurso existente dentro del ordenamiento jurídico de un Estado, mediante el cual no se resuelve el litigio planteado por una demora injustificada en el procedimiento, pueda ser considerado como un recurso efectivo. ${ }^{14}$

Importa esclarecer que, a Corte ${ }^{15}$ assinalou, em reiteradas oportunidades, que a garantia do recurso efetivo constitui um dos pilares básicos, não só da Convenção Americana, mas do próprio Estado de Direito, no contexto de sociedade democrática no sentido atribuído pela Convenção, e que para que o Estado cumpra esse postulado do artigo da Convenção, não basta que os recursos existam formalmente, mas que os mesmos possuam efetividade. ${ }^{16}$ Isso, em outras palavras, significa que esses recursos devem permitir ao indivíduo a possibilidade real de interpor um recurso que seja simples e rápido. O que leva a concluir-se que qualquer norma ou medida que impeça ou dificulte o uso dos

${ }^{12}$ CORTE IDH. Caso Ivcher Bronstein vs. Perú. Fondo, Reparaciones y Costas. Sentencia de 6 de febrero de 2001. Serie C n. 74, párrafo 136, p. 56. Ver também, Caso del Tribunal Constitucional, supra nota 8, párr. 89; e Garantias Judiciais en Estados de Emergencia (arts. 27.2, 25 y 8 Convención Americana sobre Derechos Humanos), supra nota 83, párr. 23.

${ }^{13}$ CORTE IDH. Caso Ivcher Bronstein vs. Perú. Fondo, Reparaciones y Costas. Sentencia de 6 de febrero de 2001. Serie C n. 74, párrafo 137.

${ }^{14}$ CORTE IDH. Caso Salvador Chiriboga vs. Ecuador. Excepción Preliminar y Fondo. Sentencia de 6 de mayo de 2008. Serie C n. 179, párr. 88.

${ }^{15}$ CORTE IDH. Caso Cantos vs. Argentina. Fondo, Reparaciones y Costas. Sentencia de 28 de Noviembre de 2002. Serie C n. 97, párr. 52.

${ }^{16}$ CORTE IDH. Caso Cantos vs. Argentina. Fondo, Reparaciones y Costas. Sentencia de 28 de Noviembre de 2002. Serie C n. 97, párr. 52. 
recursos pertinentes configura a violação do direito ao acesso à justiça, sob a modalidade consagrada no artigo 25 da Convenção Americana. ${ }^{17}$

Portanto, segundo Cançado Trindade (2007, p. 658) a disposição do artigo 25 da Convenção encontra-se intimamente vinculada à obrigação geral dos Estados, igualmente consagrada nos tratados de direitos humanos, de respeitar os direitos nestes consagrados, e assegurar o livre e pleno exercício dos mesmos a todas as pessoas sobre suas respectivas jurisdições. Encontra-se ademais vinculada às garantias do devido processo legal (artigo $8 \mathrm{da}$ Convenção), na medida em que assegura o acesso à justiça. Desse modo, mediante a consagração do direito a um recurso efetivo junto aos juízes e tribunais nacionais competentes, das garantias do devido processo e da obrigação geral de garantia dos direitos protegidos, a Convenção Americana (artigo 25, 8 e 1(1)), e outros tratados de direitos humanos, atribuem funções de proteção ao direito interno dos Estadosparte. (TRINDADE, 2007, p. 658).

Em relação aos artigos 8.1 e 25.1, vale destacar ainda que a Corte Interamericana, na interpretação desses dispositivos, recorda que a proteção Internacional dos Direitos Humanos tem por fim proporcionar ao indivíduo os meios de proteção dos direitos humanos reconhecidos internacionalmente frente ao Estado. ${ }^{18} \mathrm{Na}$ jurisdição internacional as partes e a matéria da controvérsia são por definição, distintas das da jurisdição interna. ${ }^{19}$ Ao estabelecer se o Estado é responsável internacionalmente pela alegada violação aos direitos consagrados nos artigos 8.1 e 25.1 da Convenção Americana, o aspecto substancial da controvérsia ante a Corte não é se no âmbito interno foi emitida sentenças ou resoluções administrativas, ou se foi aplicada ou não determinadas disposições de direito interno, em relação às violações que se alegam, foram cometidas em prejuízo das presumidas vítimas dos fatos, mas verifica-se se os processos internos permitiram que se lhes fosse garantido um verdadeiro acesso à justiça, conforme os estandartes previstos na Convenção Americana, para determinar os direitos que estavam em controvérsia. ${ }^{20}$

${ }^{17}$ CORTE IDH. Caso Cantos vs. Argentina. Fondo, Reparaciones y Costas. Sentencia de 28 de Noviembre de 2002. Serie C n. 97, párr. 52.

${ }^{18}$ CORTE IDH. Caso Trabajadores Cesados del Congreso (Aguado Alfaro y otros) vs. Perú. Excepciones Preliminares, Fondo, Reparaciones y Costas. Sentencia de 24 de Noviembre de 2006. Serie C n. 158, párr. 107.

${ }^{19}$ CORTE IDH. Caso Trabajadores Cesados del Congreso (Aguado Alfaro y otros) vs. Perú. Excepciones Preliminares, Fondo, Reparaciones y Costas. Sentencia de 24 de Noviembre de 2006. Serie C n. 158, párr. 107.

${ }^{20}$ CORTE IDH. Caso Trabajadores Cesados del Congreso (Aguado Alfaro y otros) vs. Perú. Excepciones Preliminares, Fondo, Reparaciones y Costas. Sentencia de 24 de Noviembre de 2006. Serie C n. 158, párr. 107. 
Portanto, tendo em vista o papel do Sistema Interamericano, que indica as deficiências da ordem jurídica doméstica, a jurisdição interna deve buscar a compatibilidade com a jurisdição internacional na promoção do acesso à justiça, sob pena de sofrer contínuas demandas na órbita internacional.

\section{O ACESSO À JUSTIÇA E OS OBSTÁCULOS NORMATIVOS E EMPÍRICOS}

$\mathrm{O}$ efetivo acesso à justiça pressupõe que os procedimentos obedeçam ao preenchimento de determinadas exigências que são ressaltadas nas considerações de Fix-Zamudio (1982, p. 49) que indicam as diretrizes necessárias para que os procedimentos sejam compatíveis com o princípio do acesso à justiça. Para tanto, entende que exige o imperativo da "celeridad, la economía procesal; amplias facultades para el juzgador, incluyendo la de suplir los errores y deficiencias del demandante, así como en la aportación de elementos de convicción”. Além disso, enumera que requer "un sistema flexible de medidas cautelares, y especialmente, puesto que los anteriores elementos podemos encontrarlos con más o menos fuerza en otros sectores del enjuiciamiento". Destaca que os efeitos "del fallo protector sean esencialmente preventivos y reparadores", o que significa dizer que, um sistema de proteção, deve evitar a violação atual ou iminente dos direitos fundamentais, e em todo o caso, possibilitar a restituição do gozo desses direitos afetados, visto que com exceção de alguns direitos de natureza patrimonial, os demais direitos que se referem à liberdade e à dignidade do indivíduos não podem ser substituídos por equivalentes. Por fim, salienta que as sentenças judiciais que outorgam a tutela devem ser medidas enérgicas e de rápida execução. (FIX-ZAMUDIO, 1982, p. 49).

A leitura da ótica da Corte que exigem a adequação normativa e empírica remete aos comentários de Bidart Campos (1998, p. 460), para quem:

[...] el derecho internacional de los derechos humanos y su recíproca jurisdicción supraestatal exige a los estados miembros del sistema alcanzar el 'resultado' de la efectividad de los derechos, con la paralela obrigación de prevenir, investigar, sancionar y reparar las violaciones, lo que autoriza a hablar de 'obligaciones de resultado' y no de 'obligaciones de medios'. A su modo, se inserta internacionalmente el derecho a la jurisdicción, o a la acción procesal como derecho humanos, o el derecho a la tutela eficaz.

Vistos os postulados necessários para que o procedimento de garantia seja compatível com a exigência da real proteção dos direitos fundamentais, salientase que a limitação do acesso à justiça pode decorrer de obstáculos normativos ou em razão de aspectos empíricos. O primeiro empecilho advém da ausência de mecanismos apropriados de proteção dos direitos humanos em consonâncias 
com as exigências dos Tratados e das Convenções Internacionais. $\mathrm{O}$ segundo decorre das circunstâncias em que existem instrumentos adequados de proteção, contudo a utilização desse recurso é inapropriada por contrariar os princípios que devem reger a proteção dos direitos humanos em juízo. Por isso, conforme observa Courtis (2006, p. 497) a Corte Interamericana vem desenvolvendo dois aspectos distintos de fatores que ensejam a responsabilidade internacional, que é o aspecto normativo e o aspecto empírico.

O aspecto normativo está relacionado com a idoneidade do recurso. Em consonância com o entendimento adotado pela Corte, essa aptidão recursal significa "su capacidad 'para establecer si se ha incurrido en una violación a los derechos humanos y proveer lo necesario para remediarla', y su posibilidad de 'dar resultados o respuestas a las violaciones de derechos humanos" (COURTIS, 2006, p. 497). Assim, Courtis (2006) salienta que o recurso "debe ofrecer la posibilidad de plantear como objeto la violación de un derecho humano y de obtener remedios adecuados frente a esas violaciones” (p. 497, grifos do autor).

A constatação das limitações normativas leva a Corte a sustentar, em reiteradas ocasiões, que todo Estado signatário da Convenção deve adotar todas as medidas para que os postulados estabelecidos na Convenção sejam efetivamente cumpridos em seu ordenamento jurídico interno, tal como determina o artigo 2 da Convenção. ${ }^{21}$ Igualmente, tem afirmado que os Estados devem adotar medidas positivas, evitar tomar iniciativas que limitam ou violem um direito fundamental, e suprimir medidas e práticas que restrinjam ou vulnerem um direito fundamental. ${ }^{22}$ Expõe que a obrigação contida no artigo 2 da Convenção advém do reconhecimento de uma norma consuetudinária que prescreve que, quando um Estado celebra uma convenção internacional, deve introduzir em seu direito interno as modificações necessárias para assegurar a execução das obrigações internacionais assumidas. ${ }^{23}$

Embora o Caso Maria da Penha vs. Brasi1 ${ }^{24}$ não fosse levado à apreciação da Corte, observa-se que a Comissão Interamericana verificou que a legislação brasileira não estava em consonância com a Convenção de Belém

${ }^{21}$ CORTE IDH. Caso Castañeda Gutman vs. México. Excepciones Preliminares, Fondo, Reparaciones y Costas. Sentencia de 6 de agosto de 2008. Serie C n. 184, párr. 132.

${ }^{22}$ CORTE IDH. Caso Castañeda Gutman vs. México. Excepciones Preliminares, Fondo, Reparaciones y Costas. Sentencia de 6 de agosto de 2008. Serie C n. 184, párr. 132.

${ }^{23}$ CORTE IDH. Caso Castañeda Gutman vs. México. Excepciones Preliminares, Fondo, Reparaciones y Costas. Sentencia de 6 de agosto de 2008. Serie C n. 184, párr. 132.

${ }^{24}$ Ver: CIDH. Informe de Fondo, $\mathbf{n}^{\mathbf{a}}$ 54/01, Maria da Penha Fernandes (Brasil), 16 de abril de 2001. 
do Pará. Visto que, não existia à época, no ordenamento jurídico brasileiro, um mecanismo apropriado de proteção à mulher. Esse déficit normativo ensejou a responsabilidade internacional do Estado Brasileiro em razão da ausência de mecanismos especificados de proteção da mulher contra a violência doméstica, que acarretava o impedimento do acesso à justiça das mulheres vítimas de violência doméstica.

A investigação dos aspectos normativos pontua as deficiências na elaboração dos instrumentos processuais necessários à efetiva proteção dos direitos humanos. As jurisprudências analisadas demonstram como a Corte Interamericana vem corrigindo os déficits normativos dos Estados-parte das Convenções Internacionais, de modo a assegurar a real proteção dos direitos humanos, que é vulnerado em razão da ausência de mecanismos internos de salvaguarda.

As limitações provenientes dos obstáculos empíricos decorrem da própria inefetividade dos Tribunais em aplicar a legislação existente que se mostra compatível com as Convenções Internacionais, mas que no caso em análise não cumpriu devidamente o seu papel de proteção efetiva aos direitos humanos.

Como esclarece Courtis (2006, p. 497), o segundo aspecto empírico está relacionado com as condições políticas e institucionais que permitem que um recurso previsto normativamente possa cumprir com o seu objetivo ou obter o resultado para o qual foi concebido. Sob essa perspectiva, entende-se que "un recurso no es efectivo cuando es 'ilusorio', demasiado gravoso para la víctima, o cuando el Estado no haya asegurado su 'debida aplicación' [...] por parte de sus autoridades judiciales” (COURTIS, 2006, p. 497). A leitura da jurisprudência da Corte elenca as circunstâncias em que o acesso à justiça foi limitado em razão desses aspectos empíricos.

O Caso Damião Ximenes Lopes vs. Brasil ${ }^{25}$ foi o primeiro envolvendo o Estado Brasileiro julgado pela Corte Interamericana de Direitos Humanos. Este caso foi encaminhado à Corte em razão da demora na prestação jurisdicional do Estado, que após 5 anos do assassinato do Sr. Damião Ximenes numa clínica psiquiátrica, o caso não havia sido resolvido internamente. Assim, verifica-se que a atuação do judiciário brasileiro mostrou-se insuficiente perante as exigências dos compromissos internacionais de proteção dos direitos humanos assumidos pelo Estado. Nesse Caso Damião, diferentemente, do Caso Maria da Penha, foi

${ }^{25}$ CORTE IDH. Caso Ximenes Lopes vs. Brasil. Fondo, Reparaciones y Costas. Sentencia de 4 de julio de 2006. Serie C n. 149. Versão em português diponível em: <http://www.corteidh.or.cr/docs/casos/articulos/series_149_por.pdf>. 
questionado não a ausência de um mecanismo específico de proteção, mas a exigibilidade de uma atuação mais efetiva do judiciário nacional que permita a investigação do caso conforme a exigência do princípio da razoável duração do processo.

\section{A CONCRETIZAÇÃO DO ACESSO À JUSTIÇA E A CONTRIBUIÇÃO DA JUSTIÇA INTERNACIONAL}

O próprio relembrar do marco histórico da internacionalização dos Direitos Humanos remete às reflexões sobre o papel relevante que a justiça internacional desempenha na proteção dos direitos humanos. A justiça internacional tem contribuído significativamente na promoção do acesso à justiça em várias circunstâncias. Esse fato é constatável por meio das mudanças introduzidas pela atuação das Cortes Internacionais que conduzem ao aprimoramento da proteção dos direitos humanos no âmbito interno.

A leitura dos julgados da Corte Interamericana revela na prática como a proteção internacional dos direitos humanos faz-se presente no contexto dos países americanos e a sua importância em cada atuação, que viabiliza a introdução de mudanças internas que convergem para eliminar os fatores de violação e conseqüente fortalecimento da proteção dos direitos humanos. À luz do caráter complementar da jurisdição internacional, constata-se a promoção do acesso à justiça em diversas oportunidades em que a justiça interna mostrouse insuficiente para a efetiva proteção dos direitos humanos.

Piovesan (2003, p. 254) menciona que a potencialidade da litigância internacional que determina os avanços no sistema interno de proteção dos direitos "é a maior contribuição que o uso do sistema internacional de proteção pode oferecer: propiciar progressos e avanços internos na proteção dos direitos humanos em um determinado Estado". Portanto, as "decisões do sistema interamericano têm permitido significativos avanços na proteção dos direitos humanos em nossa região, propiciando reformas legislativas e mudanças em políticas públicas". (PIOVESAN, 2006). De modo que, "os parâmetros protetivos internacionais têm assumido uma dupla vocação: estimular avanços e evitar retrocessos no regime de proteção de direitos”. (PIOVESAN, 2006).

Destarte, verifica-se o papel dos Tribunais Internacionais na promoção do acesso à justiça e sua relevância como operador de mudanças que possibilita a consolidação das garantias de proteção dos direitos humanos no âmbito doméstico. Diversas são as oportunidades em que o empenho da justiça internacional possibilitou as mudanças na ordem jurídica interna, ampliando, com isso, a proteção dos direitos humanos. Sopesa-se a influência dos julgados 
da Corte por intermédio da análise dos julgados que condenaram os Estados. Em vários momentos a Corte vem atuando no sentido de: a) "romper com o legado do regime autoritário ditatorial, responsabilizando-os pelas práticas de maustratos, tortura, desaparecimento forçado, detenção ilegal e execução sumária"; ${ }^{26}$ b) "assegurar justiça, combatendo a impunidade nos casos de transição democrática, exigindo-lhes o direito à verdade, com a anulação de imunidades e leis de anistia"27; c) "fortalecer instituições democráticas e o Estado de Direito, garantindo acesso à justiça, proteção judicial e independência judicial”; 28 e d) "proteger direitos de grupos socialmente vulneráveis, como povos indígenas ${ }^{29}$, as crianças $^{30}$, as populações afro-descentes ${ }^{31}$ os portadores de deficiências ${ }^{32}$, as mulheres ${ }^{33}$, os migrantes ${ }^{34}$, dentre outros”. (PIOVESAN, 2006).

O alcance da ordem jurídica internacional na consolidação da proteção dos direitos humanos no âmbito interno dos Estados-parte é, igualmente, destacado por Annoni (2008, p. 111) ao assinalar que:

${ }^{26}$ Ver, CORTE IDH. Caso Velásquez Rodríguez vs. Honduras. Fondo. Sentencia de 29 de julio de 1988. Serie C n. 4; CORTE IDH. Caso Godínez Cruz vs. Honduras. Fondo. Sentencia de 20 de enero de 1989. Serie C n. 5; CORTE IDH. Caso Aloeboetoe y otros vs. Surinam. Fondo. Sentencia de 4 de diciembre de 1991. Serie C n. 11; CORTE IDH. Caso El Amparo vs. Venezuela. Fondo. Sentencia de 18 de enero de 1995. Serie C n. 19; CORTE IDH. Caso Neira Alegría y otros vs. Perú. Fondo. Sentencia de 19 de enero de 1995. Serie C No. 20; CORTE IDH. Caso Caballero Delgado y Santana vs. Colombia. Fondo. Sentencia de 8 de diciembre de 1995. Serie C n. 22; CORTE IDH. Caso Garrido y Baigorria vs. Argentina. Fondo. Sentencia de 2 de febrero de 1996. Serie C n. 26.

${ }^{27}$ Ver, CORTE IDH. Caso Barrios Altos vs. Perú. Fondo. Sentencia de 14 de marzo de 2001. Serie C No. 75; Corte IDH. Caso Almonacid Arellano y otros vs. Chile. Excepciones Preliminares, Fondo, Reparaciones y Costas. Sentencia de 26 de septiembre de 2006. Serie C n. 154.

${ }^{28}$ Ver, CORTE IDH. Caso del Tribunal Constitucional vs. Perú. Fondo, Reparaciones y Costas. Sentencia de 31 de enero de 2001. Serie C n. 71; CORTE IDH. Caso Ivcher Bronstein vs. Perú. Fondo, Reparaciones y Costas. Sentencia de 6 de febrero de 2001. Serie C n. 74; CORTE IDH. Caso Acevedo Jaramillo y otros vs. Perú. Excepciones Preliminares, Fondo, Reparaciones y Costas. Sentencia de 7 de febrero de 2006. Serie C n. 144; CORTE IDH. Caso Claude Reyes y otros vs. Chile. Fondo, Reparaciones y Costas. Sentencia de 19 de septiembre de 2006. Serie C n. 151; CORTE IDH. Caso Trabajadores Cesados del Congreso (Aguado Alfaro y otros) vs. Perú. Excepciones Preliminares, Fondo, Reparaciones y Costas. Sentencia de 24 de Noviembre de 2006. Serie C n. 158; CORTE IDH. Caso Apitz Barbera y otros ("Corte Primera de lo Contencioso Administrativo") vs. Venezuela. Excepción Preliminar, Fondo, Reparaciones y Costas. Sentencia de 5 de agosto de 2008. Serie C n. 182; CORTE IDH. Caso Tristán Donoso vs. Panamá. Excepción Preliminar, Fondo, Reparaciones y Costas. Sentencia de 27 de enero de 2009 Serie C 
[...] o impacto dos tratados internacionais de direitos humanos nos ordenamentos jurídicos internos dos Estados membros tem provocado um movimento de alterações legislativas com o propósito de harmonizar as garantias internacionais aos direitos internacionais reconhecidos. De igual modo, essas modificações legislativas têm gerado movimentos em prol da efetividade desses direitos, cuja mera positivação no plano interno já não é suficiente à sua observância.

Essa influência interferiu para o desencadeamento das atuais reformas do Judiciário. Por isso, entende-se que:

[...] no Brasil, a recente reforma do Poder Judiciário é fruto desse movimento de influência do Direito Internacional dos direitos humanos em prol da eficácia desses direitos no plano interno dos Estados, tendo resultado, entre outras garantias, o reconhecimento constitucional do direito à razoável duração do processo. (ANNONI, 2008, p. 111).

Além do reconhecimento formal do princípio da razoável duração do processo, cita-se no direito brasileiro a Lei Maria da Penha ${ }^{35}$ que veio a regulamentar a Convenção de Belém do Pará, que significa o fortalecimento

n. 193; CORTE IDH. Caso Ríos y otros vs. Venezuela. Excepciones Preliminares, Fondo, Reparaciones y Costas. Sentencia de 28 de enero de 2009. Serie C n. 194; CORTE IDH. Caso Perozo y otros vs. Venezuela. Excepciones Preliminares, Fondo, Reparaciones y Costas. Sentencia de 28 de enero de 2009. Serie C n. 195.

${ }^{29}$ Ver, CORTE IDH. Caso de la Comunidad Mayagna (Sumo) Awas Tingni vs.

Nicaragua. Fondo, Reparaciones y Costas. Sentencia de 31 de agosto de 2001. Serie C n. 79; CORTE IDH. Caso de la Comunidad Moiwana vs. Surinam. Excepciones Preliminares, Fondo, Reparaciones y Costas. Sentencia 15 de junio de 2005. Serie C n. 124; CORTE IDH. Caso Comunidad Indígena Yakye Axa Vs. Paraguay. Fondo Reparaciones y Costas. Sentencia 17 de junio de 2005. Serie C n. 125; CORTE IDH. Caso Yatama vs. Nicaragua. Excepciones Preliminares, Fondo, Reparaciones y Costas. Sentencia de 23 de junio de 2005. Serie C n. 127; CORTE IDH. Caso Comunidad Indígena Sawhoyamaxa vs. Paraguay. Fondo, Reparaciones y Costas. Sentencia de 29 de marzo de 2006. Serie C n. 146; CORTE IDH. Caso del Pueblo Saramaka. vs. Surinam. Excepciones Preliminares, Fondo, Reparaciones y Costas. Sentencia de 28 de noviembre de 2007. Serie C n. 172.

${ }^{30}$ Ver, CORTE IDH. Caso de los "Niños de la Calle" (Villagrán Morales y otros) vs. Guatemala. Fondo. Sentencia de 19 de noviembre de 1999. Serie C n. 63, Serie C n. 130, CORTE IDH. Condición Jurídica y Derechos Humanos del Niño. Opinión Consultiva OC-17/02 del 28 de agosto de 2002. Serie A n. 17.

${ }^{31}$ Ver, CIDH. Relatório no 66/06 (mérito), Caso Simone André Diniz vs. Brasil. 21 de outubro de 2006.

${ }^{32}$ Ver, CORTE IDH. Caso Ximenes Lopes vs. Brasil. Fondo, Reparaciones y Costas. Sentencia de 4 de julio de 2006. Versão em português. Serie C n. 149.

${ }^{33}$ Ver, CORTE IDH. Caso del Penal Miguel Castro Castro vs. Perú. Fondo, Reparaciones y Costas. Sentencia de 25 de noviembre de 2006. Serie C n. 160; CORTE IDH. Caso Ríos y otros vs. Venezuela. Excepciones Preliminares, Fondo, Reparaciones y Costas. Sentencia de 28 de enero de 2009. Serie C n.194. CIDH. 
da proteção dos direitos das mulheres no contexto brasileiro. Nota-se, também, que outras circunstâncias relevantes, em que a Justiça Internacional foi determinante para possibilitar a introdução de mudanças na ordem jurídica brasileira. (PIOVESAN, 2003, p. 312). Por exemplo, as denúncias dos abusos cometidos pelos policiais militares foram importantes para a adoção da Lei n. 9.299/96, que transferiu da Justiça Militar para a Justiça comum o julgamento dos crimes dolosos contra a vida praticados pelos policiais militares. ${ }^{36} \mathrm{O}$ caso do assassinato de uma estudante por uma deputado estadual ${ }^{37}$ foi essencial para a introdução da Emenda Constitucional n. 35/2001, que limita a imunidade parlamentar no Brasil. A denúncia de discriminação contra as mães adotivas e seus filhos, ${ }^{38}$ decorrentes de uma decisão do Supremo Tribunal Federal que negou o direito à licença-gestante à mãe adotiva, foi crucial para a aprovação da Lei n. 10.421/2002, que garante os mesmos direitos às mães adotivas. Os casos relacionados com a violência contra os defensores de Direitos Humanos foram cruciais para adoção do Programa Nacional de Proteção aos Defensores. ${ }^{39}$ Os casos envolvendo conflitos agrários e trabalho escravo ${ }^{40}$ foram essenciais para o desenvolvimento do Programa Nacional para a Erradicação do Trabalho Escravo. (PIOVESAN, 2003, p. 312).

A implementação dessas mudanças leva Piovesan (2003, p. 312) a concluir

Maria da Penha Fernandes (Brasil). Informe de Fondo, nº 54/01, 16 de abril de 2001.

${ }^{34}$ Ver, CORTE IDH. Caso de las Niñas Yean y Bosico vs. República Dominicana. Excepciones Preliminares, Fondo, Reparaciones y Costas. Sentencia de 8 de septiembre de 2005, ver também: CORTE IDH. Condición Jurídica y Derechos de los Migrantes Indocumentados. Opinión Consultiva OC-18/03 del 17 de septiembre de 2003. Serie A n. 18.

${ }^{35}$ Lei 11.340/06. A constitucionalidade da Lei Maria da Penha é objeto de discussão no STF em virtude da Ação Declaratória de Constitucionalidade n. ${ }^{\circ} 19$, que tem por objeto a declaração negativa de violação da Constituição quanto a: i) ao princípio da igualdade (art. 5o, I, da CF); ii) à competência atribuída aos Estados para fixar a organização judiciária local (art. 125, §1ํㅡ c/c Art. 96, II, “d”) e iii) à competência dos juizados especiais (art. 98, I, da CF). In: BRASIL. Supremo Tribunal Federal. ADC n.․ 19 (petição inicial e decisão liminar). Requerente: Presidente da República. Relator: Ministro Marco Aurélio. Brasília, 21 de dezembro de 2007.

${ }^{36}$ Ver: CIDH. Caso 10301 (Caso "Parque São Lucas).

${ }^{37}$ Ver: CIDH. Caso 12263 (Caso Márcia Barbosa).

${ }^{38}$ Ver: CIDH. Caso 12378.

${ }^{39}$ Ver: CIDH. Caso 12397; CIDH. Caso 1258 e CIDH. Caso 12397.

40 Ver: CIDH. Caso 11287, CIDH. Caso 11289, CIDH. Caso 11405, CIDH. Caso 11495, CIDH. Caso 11556, CIDH. Caso 11820, CIDH. Caso 11517, CIDH. Caso 12066, CIDH. Caso 12200, CIDH. Caso 12310, CIDH. Caso 12353, CIDH. Caso 12478 e CIDH. Caso 12332. 
que "o sistema interamericano de proteção dos direitos humanos oferece importantes estratégias de ação, potencialmente capazes de contribuir para o reforço da promoção dos direitos humanos no Brasil”.

Registra-se que no Estado Chileno foram introduzidas modificações legislativas em razão da sentença da Corte, dentre elas a correção do texto constitucional, que limitava a liberdade de expressão e de pensamento, no Caso a "Última de Tentação de Cristo". ${ }^{41}$ Além disso, recentemente, em cumprimento às determinações do Caso Claude Reyes e outros vs. Chile, o Estado Chileno editou uma lei dispondo que a partir de abril de $2009^{42}$, quando entrar em vigor essa norma, o requerimento de informação feito por qualquer cidadão a um órgão público, sobre uma resolução de sua área, deverá ser respondido no máximo em 20 dias. (HITTERS, 2008, p. 152). Diante da implementação da decisão a Corte Interamericana, salientou que:

[...] valora positivamente la promulgación y publicación de la Ley de Transparencia de la Función Pública y Acceso a la Información de la Administración del Estado, que reglamenta el artículo 8 de la Constitución Política de Chile y establece el procedimiento para garantizar el acceso a la información bajo el control del Estado. ${ }^{43}$

O cumprimento integral da sentença no Caso la Comunidad Mayagna (Sumo) Awas Tingni vs. Nicarágua ${ }^{44}$ foi fundamental para a proteção dos povos indígenas. Essa importância é destacada pela Corte que:

[...] valora positivamente que el Estado ha dado cumplimiento integral a las medidas de reparación ordenadas por este Tribunal en la Sentencia de fondo, reparaciones y costas de 31 de agosto de 2001, en lo que representa un importante precedente legal para el Derecho Internacional de los Derechos Humanos, por ser éste un caso paradigmático en el reconocimiento al derecho de propiedad de los pueblos indígenas, así como de sus valores, usos y costumbres ancestrales. ${ }^{45}$

${ }^{41}$ Ver: CORTE IDH. Caso "La Última Tentación de Cristo" (Olmedo Bustos y otros) vs. Chile. Fondo, Reparaciones y Costas. Sentencia de 5 de febrero de 2001. Serie C n. 73.

${ }^{42}$ Ver: CORTE IDH. Caso Claude Reyes y otros vs. Chile. Supervisión de Cumplimiento de Sentencia. Resolución de la Corte Interamericana de Derechos Humanos de 24 de noviembre de 2008.

${ }^{43}$ CORTE IDH. Caso Claude Reyes y otros vs. Chile. Supervisión de Cumplimiento de Sentencia. Resolución de la Corte Interamericana de Derechos Humanos de 24 de noviembre de 2008, párr. 13.

${ }^{44}$ Ver: CORTE IDH. Caso de la Comunidad Mayagna (Sumo) Awas Tingni vs. Nicaragua. Fondo, Reparaciones y Costas. Sentencia de 31 de agosto de 2001. Serie C n. 79.

${ }^{45}$ CORTE IDH. Caso de la Comunidad Mayagna (Sumo) Awas Tingni vs. Nicaragua. Supervisión de Cumplimiento de Sentencia. Resolución de la Corte Interamericana de Derechos Humanos de 3 de abril de 2009, párr. 15. 
No contexto Peruano, no Castillo Páez vs. Perúu ${ }^{46}$ o responsável pelos crimes foi punido. ${ }^{47}$ Ante o cumprimento do dever de investigar, a Corte manifestou que:

[...] valora positivamente el cumplimiento del punto resolutivo segundo de la Sentencia de reparaciones dictada en el presente caso, en lo que se refiere a la investigación penal de los hechos y la identificación y sanción de los responsables de la desaparición forzada de Ernesto Castillo Páez. ${ }^{48}$

Vale enfatizar a proeminência da resolução interna do Caso Castillo Paez, pois conforme postula Riviera Paz (2006, p. 37): "no hay duda de que los fundamentos expuestos en esta resolución constituirán un precedente judicial de obligatoria mención y referencia en otros procesos judiciales que se pudiesen seguir por este delito".

Em razão da declaração de invalidade da Lei de Anistia peruana foi aberta a viabilidade de punição dos responsáveis pelos massacres de Barrios Altos ${ }^{49} \mathrm{e}$ La Cantuta ${ }^{50}$, nos quais foram responsabilizados, dentre eles, o ex-Presidente da República Alberto Fujimori ${ }^{51}$. Assim, ineditamente, o Estado Peruano cumpriu com o dever de justiça interna ${ }^{52}$, que só foi possível em razão do reconhecimento pela Corte Interamericana da incompatibilidade entre as Leis de Anistia e a proteção internacional dos direitos humanos.

${ }^{46}$ Ver: CORTE IDH. Caso Castillo Páez vs. Perú. Reparaciones y Costas. Sentencia de 27 de noviembre de 1998. Serie C no. 43.

${ }^{47}$ CORTE IDH. Caso Castillo Páez vs. Perú. Supervisión de Cumplimiento de Sentencia. Resolución de la Corte Interamericana de Derechos Humanos de 3 de abril de 2009, párr. 8, f.

${ }^{48}$ CORTE IDH. Caso Castillo Páez vs. Perú. Supervisión de Cumplimiento de Sentencia. Resolución de la Corte Interamericana de Derechos Humanos de 3 de abril de 2009, párr. 21.

Verifica-se que ainda está pendente de cumprimento a localização dos restos mortais da vítima. In: CORTE IDH. Caso Castillo Páez vs. Perú. Supervisión de Cumplimiento de Sentencia. Resolución de la Corte Interamericana de Derechos Humanos de 3 de abril de 2009, párr. 22.

${ }^{49}$ Ver: CORTE IDH. Caso Barrios Altos vs. Perú. Fondo. Sentencia de 14 de marzo de 2001. Serie C n. 75.

${ }^{50}$ Ver: CORTE IDH. Caso La Cantuta vs. Perú. Fondo, Reparaciones y Costas. Sentencia de 29 de noviembre de 2006. Serie C n. 162.

${ }^{51}$ PERU. CORTE SUPREMA DE JUSTICIA DE LA REPÚBLICA. SALA PENAL ESPECIAL. Casos Barrios Altos, La Cantuta y sótanos SIE. Expediente n. AV 192001, del siete de abril de 2009.

${ }^{52}$ Ver: CORTE IDH. Caso Barrios Altos vs. Perú. Supervisión de Cumplimiento de Sentencia. Resolución de la Corte Interamericana de Derechos Humanos de 04 de agosto de 2008, párrs. 23 ao 28. 
Observa-se que satisfação das determinações internacionais introduz mudanças significativas para alcançar o fortalecimento da proteção dos direitos humanos, que indica os avanços na proteção em razão da atuação da Corte Interamericana e a potencialidade da litigância internacional.

\section{CONSIDERAÇÕES FINAIS}

O grande "impulso" contemporâneo para a positivação dos Direitos Humanos foi, seguramente, a radical negação da dignidade humana em eventos como o Holocausto, durante a segunda guerra mundial. E no continente americano, a imagem de governos ditatoriais submetendo seus cidadãos às variadas espécies de barbarismos fornecem também um importante referencial negativo, que encontra nos tratados internacionais de direitos humanos uma contundente resposta.

Entretanto, como foi possível observar dos inúmeros casos citados acima, a Corte Interamericana exerce suas competências decisórias num contexto que é, no essencial, muito diverso daquele encontrado nos paradigmas de "terrorismo de Estado”. De um modo geral os Estados nacionais sobre os quais recaem a condenações da Corte não são ditaduras, mas sim democracias, ainda que imperfeitas em muitos aspectos. São Estados nacionais que, democraticamente, decidiram aderir ao sistema da Carta interamericana como forma de consolidar - e não abdicar - suas instituições democráticas nacionais, as quais demandam uma boa dose de sua autonomia política frente a outros Estados. E especificamente no tocante ao direito ao "acesso à justiça", a Corte deve decidir se dentre essas "imperfeições” nas instituições democráticas encontram-se (i) a ausência de mecanismos institucionais que permitem o acesso ou se (ii) tais mecanismos, embora formalmente existentes, na prática são insuficientes para atingir o objetivo proposto. Ocorre que a decisão da Corte sobre a adequação dos Estados nacionais aos direitos enumerados na Carta de Direitos Humanos, neste aspecto como em outros, de modo algum é uma questão de "tudo ou nada": as alternativas não são (a) anular a soberania dos Estados-membro ou (b) reconhecer uma soberania nacional praticamente absoluta, atribuindo aos Estados todo o poder relevante para decidir sobre a implementação da Carta. Como foi possível perceber, essas são hipóteses extremadas, ambas incompatíveis com o regime interamericano. A primeira opção contraria o propósito de consolidar as instituições democráticas nestes Estados, o que requer boa dose de soberania nacional, sem a qual as instituições políticas democráticas perdem sentido e eficácia. A segunda opção contraria o propósito dos próprios Estados-membro, que decidiram explicitamente aceitar os princípios da Carta interamericana. 
Os casos discutidos mostram como é possível, na jurisprudência da Corte sobre acesso à justiça, compatibilizar as demandas legítimas de soberania nacional com as reivindicações igualmente legítimas sobre a concretização de direitos humanos frente ao poder Estatal. Em se tratando de "democracias imperfeitas" a Corte deve atuar para promover avanços e evitar retrocessos, preservando as instituições políticas democráticas atualmente existentes. Isso aponta para uma jurisprudência que estimula mudanças progressivas, as quais são necessariamente internas aos Estados, mudanças como a alteração da legislação e a execução de políticas públicas. Uma tal jurisprudência, criteriosa na denuncia das insuficiências das atuais democracias na proteção do acesso à justiça mas preocupada em preservar a estabilidade das instituições democráticas, é plenamente justificada. Afinal, se os direitos humanos - dentre eles o direito ao acesso à justiça - asseguram aos cidadãos uma esfera inviolável de proteção contra a qual nenhum Estado pode legitimamente se opor, por outro lado a efetivação dos direitos humanos exige instituições políticas nacionais ou que resultam diretamente de pactos celebrados entre Estados nacionais. Os casos discutidos demonstram que esta tarefa de modo algum é simples, embora em inúmeras oportunidades seja viável.

\section{REFERÊNCIAS}

ABREGÚ, Martín. La aplicación del Derecho Internacional de los Derechos Humanos por los tribunales locales: una introducción. In: ABREGÚ, Martín; COURTIS, Chistian (Coord.). La aplicación de los tratados sobre derechos humanos por los tribunales locales. Buenos Aires: Del Puerto, 2004. p. 3-31.

ANNONI, Danielle. O direito humano de acesso à justiça no Brasil. Porto Alegre: Safe, 2008.

BIDART CAMPOS, German J. Hierarquía y prelación de normas en un sistema internacional de derechos humanos. In: LIBER Amicorum, Héctor FixZamudio. San José, Costa Rica: Corte Interamericana de Derechos Humanos, Unión Europea, 1998. v. 2, p. 447-79.

CAPPELlETTI, Mauro; GARTH, Bryant. Acesso à Justiça. Trad. Ellen Gracie Northfleet. Porto Alegre: Safe, 1988.

CINTRA, Antonio Carlos de Araújo; GRINOVER, Ada Pellegrini; DINAMARCO, Cândido Rangel. Teoria geral do processo. 19. ed. São Paulo: Malheiros, 2003. 
COMISSÃO INTERAMERICANA DE DERECHOS HUMANOS. El acceso a la justicia como garantía de los derechos económicos, sociales y culturales. Estudio de los estándares fijados por el sistema interamericano de derechos humanos, 2007.

CORTE IDH. Caso Ivcher Bronstein vs. Perú. Fondo, Reparaciones y Costas. Sentencia de 6 de febrero de 2001. Serie C n. 74.

. Caso Cantos vs. Argentina. Fondo, Reparaciones y Costas. Sentencia de 28 de Noviembre de 2002. Serie C n. 97.

. Caso Trabajadores Cesados del Congreso (Aguado Alfaro y otros) vs. Perú. Excepciones Preliminares, Fondo, Reparaciones y Costas. Sentencia de 24 de Noviembre de 2006. Serie C n. 158.

. Caso Salvador Chiriboga vs. Ecuador. Excepción Preliminar y Fondo. Sentencia de 6 de mayo de 2008. Serie C n. 179.

- Caso Castañeda Gutman vs. México. Excepciones Preliminares, Fondo, Reparaciones y Costas. Sentencia de 6 de agosto de 2008. Serie C n. 184.

Caso Claude Reyes y otros vs. Chile. Supervisión de Cumplimiento de Sentencia. Resolución de la Corte Interamericana de Derechos Humanos de 24 de noviembre de 2008.

. Caso Castillo Páez vs. Perú. Supervisión de Cumplimiento de Sentencia. Resolución de la Corte Interamericana de Derechos Humanos de 3 de abril de 2009.

. Caso de la Comunidad Mayagna (Sumo) Awas Tingni vs. Nicaragua. Supervisión de Cumplimiento de Sentencia. Resolución de la Corte Interamericana de Derechos Humanos de 3 de abril de 2009.

COURTIS, Chistian. El derecho a um recurso rápido, sencillo y efectivo frente a afectaciones coletivas de derechos humanos. In: ABRAMOVICH, Victor; BOVINO, Alberto; COURTIS, Chistian (Coord.). La aplicación de los tratados sobre derechos humanos en el ámbito local: la experiencia de una década. Buenos Aires: Del Puerto, 2006. p. 491-524.

FIX ZAMUDIO, Héctor. La protección jurídica y procesal de los derechos humanos ante las jurisdicciones nacionales. Ciudad do México: Civitas, 1982.

HITTERS, Juan Carlos. ¿Son vinculantes los pronunciamientos de la Comisión y de la Corte Interamericana de Derechos Humanos? (control de 
constitucionalidad y convencionalidad). In: Revista Iberoamericana de Derecho Procesal Constitucional, México, n. 10, p. 131-156, dic. 2008,

LESDEMA, Héctor Faúndez. El agotamiento de los recursos internos en el sistema interamericano de protección de los derechos humanos. In: XXV CURSO Interdisciplinario en Derechos Humanos. San José, Costa Rica: IIDH, 9-20 jul. 2007.

MARINONI, Luiz Guilherme. Efetividade do processo e tutela de urgência. Porto Alegre: Safe, 1994.

PIOVESAN, Flávia. Princípio da complementariedade e soberania. Texto baseado nas notas taquigráficas proferida no Seminário Internacional "O Tribunal Penal Internacional e a Constituição Brasileira”, promovido pelo Centro de Estudos Judiciários do Conselho da Justiça Federal, em 30 de setembro de 1999, no auditório do Superior Tribunal de Justiça, em Brasília - DF.

. Temas de direitos humanos. 2. ed. rev. ampl. e atual. São Paulo: Max Limonad, 2003.

. Proteção internacional dos direitos econômicos, sociais e culturais. In: SARLET, Ingo Wolfgang (Org.). Direitos fundamentais sociais: estudo constitucional, internacional e comparado. Rio de Janeiro: Renovar, 2003, p. 233-26.

. Justiça global e avanços locais. Folha de São Paulo, São Paulo, 08 set. 2006. Seção Opinião-Tendências/Debates.

. Direitos humanos e o direito constitucional internacional. 7. ed. São Paulo: Saraiva, 2006.

RAMOS, André de Carvalho. Teoria geral dos direitos humanos na ordem internacional. Rio de Janeiro: Renovar, 2005.

RIVIERA PAZ, Carlos. Una sentencia histórica. La desaparición forzada de Ernesto Castillo Páez. Lima: Instituto de Defensa Legal, 2006.

TORO HUERTA, Mauricio Ivan del. La apertura constitucional al derecho internacional de los derechos humanos en la era de la mundialización y sus consecuencias en la práctica judicial. Boletín Mexicano de Derecho Comparado. Nueva Serie, año 38, n. 112, p. 325-363, enero-abr. 2005,

TRINDADE, Antônio Augusto Cançado. A regra do esgotamento dos recursos internos revisitada: desenvolvimentos jurisprudenciais recentes no âmbito da 
proteção internacional dos direitos humanos. In: LIBER Amicorum, Héctor FixZamudio. San José, Costa Rica: Corte Interamericana de Derechos Humanos, Unión Europea, 1998. v. 1.

- Derecho Internacional de los derechos humanos: esencia y trascendencia. México: Porrúa, 2007.

VENTURA ROBLES, Manuel E. La jurisprudencia de la Corte Interamericana de Derechos Humanos en materia de acceso a la justicia e impunidad. Disponível em: <http://www2.ohchr.org/spanish/issues/democracy/costarica/ docs/PonenciaMVentura.doc>. Acesso em: 02 fev. 2008.

Artigo recebido em 15/09/09 e aceito em 26/09/09 